\title{
Comparative efficacy of long-acting $\beta 2$-agonists as monotherapy for chronic obstructive pulmonary disease: a network meta-analysis
}

\author{
This article was published in the following Dove Press journal: \\ International Journal of COPD \\ 19 January 2017 \\ Number of times this article has been viewed
}

\author{
James F Donohue' \\ Keith A Betts ${ }^{2}$ \\ Ella Xiaoyan Du \\ Pablo Altman ${ }^{3}$ \\ Pankaj Goyal ${ }^{4}$ \\ Dorothy L Keininger ${ }^{4}$ \\ Jean-Bernard Gruenberger ${ }^{4}$ \\ James E Signorovitch \\ 'Department of Pulmonary Diseases \\ and Critical Care Medicine, The \\ University of North Carolina, Chapel \\ Hill, NC, ${ }^{2}$ Analysis Group, Inc., Los \\ Angeles, CA, ${ }^{3}$ Novartis Pharmaceutical \\ Corporation, East Hanover, NJ, \\ USA; ${ }^{4}$ Novartis Pharma AG, Basel, \\ Switzerland; ${ }^{5}$ Analysis Group, Inc., \\ Boston, MA, USA
}

Correspondence: James F Donohue Division of Pulmonary Medicine, University of North Carolina, 420 Burnett-Womack Building CB-7020, Chapel Hill, NC 27599-7020, USA

Tel +19197189512

$\mathrm{Fax}+19197189516$

Email jdonohue@med.unc.edu
Purpose: Long-acting $\beta 2$-agonists (LABAs) have demonstrated efficacy in patients with COPD in clinical trials. The purpose of this study was to assess the comparative efficacy of all available dosages of all LABA monotherapies using a network meta-analysis.

Methods: A systematic literature review identified 33 randomized controlled trials of LABA monotherapies (salmeterol $50 \mu \mathrm{g}$ twice daily [BID]; formoterol $12 \mu \mathrm{g} \mathrm{BID}$; indacaterol 75, 150, and $300 \mu \mathrm{g}$ once daily [OD]; olodaterol 5 and $10 \mu \mathrm{g}$ OD, and vilanterol $25 \mu \mathrm{g}$ OD). Clinical efficacy was evaluated at 12 and 24 weeks in terms of trough forced expiratory volume in 1 second $\left(\mathrm{FEV}_{1}\right)$, transition dyspnea index focal score, St George's Respiratory Questionnaire total score, and rate of COPD exacerbations. The relative effectiveness of all LABA monotherapies was estimated by Bayesian network meta-analysis.

Results: At 12 and 24 weeks, indacaterol 300 and $150 \mu \mathrm{g}$ OD were associated with statistically significant improvement in trough $\mathrm{FEV}$, compared to all other LABA monotherapies; vilanterol $25 \mu \mathrm{g}$ OD was superior to formoterol $12 \mu \mathrm{g}$ BID. At 12 weeks, indacaterol $75 \mu \mathrm{g}$ OD was associated with significant improvement in trough $\mathrm{FEV}_{1}$ compared to formoterol $12 \mu \mathrm{g}$ BID and olodaterol ( 5 and $10 \mu \mathrm{g}$ OD); salmeterol $50 \mu \mathrm{g}$ BID was superior to formoterol $12 \mu \mathrm{g}$ BID and olodaterol $5 \mu \mathrm{g}$ OD. Indacaterol $300 \mu \mathrm{g}$ OD was also associated with significant improvement in transition dyspnea index focal score compared to all other LABAs at 12 or 24 weeks. Indacaterol $150 \mu \mathrm{g}$ OD had significantly better results in exacerbation rates than olodaterol $5 \mu \mathrm{g}$ and olodaterol $10 \mu \mathrm{g}$ OD.

Conclusion: Indacaterol $300 \mu \mathrm{g}$, followed by 150 and $75 \mu \mathrm{g}$, were the most effective LABA monotherapies for moderate to severe COPD.

Keywords: COPD, long-acting $\beta 2$-agonists, network meta-analysis, systematic literature review, indacaterol

\section{Introduction}

COPD is a chronic, progressive disease of the lung characterized by poor airflow, shortness of breath, and cough, and leads to long-term decline in lung function. Approximately 5\% of the world population ( 329 million people) are affected by $\mathrm{COPD},{ }^{2}$ which is correlated with tobacco use, ${ }^{3}$ older age, ${ }^{4}$ pollution,,${ }^{5,6}$ and genetics. ${ }^{1,7,8}$ This disease is a major cause of morbidity and mortality, and was responsible for 3 million deaths globally as estimated by the World Health Organization in 2012.1,6,9,10 The World Health Organization also estimates that over one-third of premature deaths attributable to COPD in low- and middle-income countries are due to indoor exposure to smoke. ${ }^{11}$ In addition, COPD patients may experience frequent exacerbations, respiratory infections, and COPD-related hospitalizations that contribute to a substantial 
social and economic burden, ${ }^{12}$ accounting for an estimated $\$ 18$ billion in direct medical costs in the USA and $\sim 38.7$ billion in the European Union. ${ }^{10}$

There is no cure for COPD, but appropriate pharmacologic therapy is critical in reducing the frequency and severity of symptoms. Bronchodilators, which alter airway smooth muscle tone, are central to the management of COPD symptoms. Long-acting $\beta 2$-agonists (LABAs) and long-acting muscarinic antagonists (LAMAs) are two commonly used bronchodilators. ${ }^{1}$ LABA monotherapy is contraindicated for patients with asthma, due to an increased risk of the exacerbation of asthma symptoms. ${ }^{13}$

A variety of LABAs with different durations of action, routes of administration, delivery devices, and associated rates of exacerbation, breathlessness, and bronchodilator effects are currently available. ${ }^{1,14}$ Commonly used LABAs include twice-daily (BID) salmeterol $50 \mu \mathrm{g}$ and formoterol $12 \mu \mathrm{g}$, which have a duration of action of 12 hours. Newer agents such as indacaterol 75/150/300 $\mu \mathrm{g},{ }^{15}$ olodaterol 5/10 $\mu \mathrm{g},{ }^{16}$ and vilanterol $25 \mu \mathrm{g}^{17}$ are given once daily (OD) with a duration of action of 24 hours. (Indacaterol 150 and $300 \mu$ g, olodaterol $10 \mu \mathrm{g}$, and vilanterol $25 \mu \mathrm{g}$ are not commercially available in the USA.) Given the variety of available LABAs for the treatment of COPD, physicians are faced with the difficulty of choosing the LABA with optimal efficacy. Randomized controlled trials (RCTs) have evaluated the efficacy of long-acting LABA monotherapies against placebo and/or short-acting LABAs. In RCTs, indacaterol was found to have a significantly greater bronchodilator effect than placebo, formoterol $12 \mu \mathrm{g}$ BID, and salmeterol $50 \mu \mathrm{g}$ BID. ${ }^{15,18,19}$ In addition, olodaterol $(5 / 10 \mu \mathrm{g})$ was superior to placebo and formoterol $12 \mu \mathrm{g} \mathrm{BID},{ }^{16,20}$ and vilanterol $25 \mu \mathrm{g}$ OD was superior to placebo. ${ }^{17,21,22}$ In addition, several earlier network meta-analyses (NMAs) have indirectly compared the efficacy among a limited number of LABAs/LAMAs. ${ }^{23,24}$ In 2013, Cope et al compared 40 RCTs in a Bayesian meta-analysis and found that indacaterol $(150 / 300 \mu \mathrm{g})$, glycopyrronium $50 \mu \mathrm{g}$, and tiotropium $5 \mu \mathrm{g}$ were superior to other LABAs, with indacaterol dominant in forced expiratory volume in 1 second $\left(\mathrm{FEV}_{1}\right)$ and St George's Respiratory Questionnaire (SGRQ) score improvement. ${ }^{23}$ In 2014, Roskell et al compared olodaterol $5 \mu \mathrm{g}$ and indacaterol $(75 / 150 \mu \mathrm{g})$ in a meta-analysis of $18 \mathrm{RCTs}$, and found no significant differences in their primary analysis. ${ }^{24}$

However, studies evaluating the comparative efficacy of all currently available LABAs, including the newer agents in different doses, have not been conducted. Thus, this study aimed to evaluate the comparative efficacy of all available
LABA monotherapy inhalers trialed in patients with moderate to severe COPD using an NMA. LABAs included in the network were salmeterol $50 \mu \mathrm{g}$ BID (inhalation powder), formoterol $12 \mu \mathrm{g}$ BID (inhalation powder), indacaterol $75 / 150 / 300 \mu \mathrm{g}$ OD (inhalation powder), olodaterol 5 and $10 \mu \mathrm{g}$ OD (inhalation spray), and vilanterol $25 \mu \mathrm{g}$ OD (inhalation powder). (Indacaterol 150 and $300 \mu \mathrm{g}$, olodaterol $10 \mu \mathrm{g}$, and vilanterol $25 \mu \mathrm{g}$ are not commercially available in the USA.) The efficacy of these LABAs was evaluated using the following outcomes: 1) trough $\mathrm{FEV}_{1}$ at 12 and 24 weeks; 2) transition dyspnea index (TDI) focal score at 12 and 24 weeks; 3) SGRQ total score at 12 and 24 weeks; and 4) rate of exacerbation.

\section{Methods}

\section{Study identification and selection}

A systematic literature review was conducted to update an earlier systematic review completed in 2013. ${ }^{23}$ The updated search was performed in MEDLINE and MEDLINE-InProcess, EMBASE, and Cochrane databases through Ovid for RCTs evaluating the efficacy of LABA monotherapies (indacaterol [indacaterol inhalation powder], salmeterol [salmeterol xinafoate inhalation powder], olodaterol [olodaterol inhalation spray], vilanterol [vilanterol inhalation powder], and formoterol [formoterol inhalation powder]) trialed in patients with moderate to severe COPD. The studies identified from the updated search spanned from January 1, 2013 to March 24, 2015, while the earlier search had extended back to $1989 .{ }^{23}$ Full-text terms and common abbreviations, listed in the Supplementary material, were used for the search strategy. Eligible studies from both the earlier and updated systematic literature reviews were included in the current meta-analysis.

All articles identified in the initial database search were screened for relevance based on title, abstract, and full-text articles. RCTs that reported at least one of the outcomes of interest for the targeted interventions among adults with moderate to severe COPD were selected. To be included into the network, trials were further required to include a comparison of at least two of the interventions of interest or one of the above interventions against placebo. The selection criteria for the study population, interventions, comparators, and outcomes are detailed in Table 1. The screening process was independently conducted by and reconciled between two researchers, and in the event of a discrepancy, a third researcher was consulted.

Trials were excluded if they were duplications, conference abstracts only, $<12$ weeks in duration, or if the patient 
Table I Study selection criteria for inclusion in the network metaanalysis

\begin{tabular}{|c|c|}
\hline Characteristic & Inclusion criteria \\
\hline Population & Adults with moderate to severe COPD \\
\hline \multirow[t]{7}{*}{ Interventions } & Monotherapies: \\
\hline & Indacaterol $(75 \mu \mathrm{g}$ OD or I50 $\mu \mathrm{g}$ OD or \\
\hline & $300 \mu \mathrm{g}$ OD) \\
\hline & Olodaterol (5 $\mu \mathrm{g}$ OD or $10 \mu \mathrm{g}$ OD) \\
\hline & Vilanterol (25 $\mu \mathrm{g}$ OD) \\
\hline & Salmeterol (50 g BID) \\
\hline & 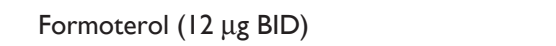 \\
\hline Comparators & Any of the interventions listed above or placebo \\
\hline \multirow[t]{4}{*}{ Outcomes } & Trough FEV , at 12 and 24 weeks \\
\hline & SGRQ total score at 12 and 24 weeks \\
\hline & TDI focal score at 12 and 24 weeks \\
\hline & Rate of exacerbation (trial duration) \\
\hline Study design & Randomized controlled clinical study \\
\hline
\end{tabular}

Abbreviations: BID, twice daily; COPD, Chronic Obstructive Pulmonary Disease; $\mathrm{FEV}_{\text {l, }}$, forced expiratory volume in I second; OD, once daily; SGRQ, St George's Respiratory Questionnaire; TDI, transition dyspnea index.

population, trial design, intervention, comparator, or outcomes did not meet the inclusion criteria (Table 1).

\section{Outcome measures}

Six continuous outcomes and one rate outcome were included in the NMA. Continuous outcomes included trough $\mathrm{FEV}_{1}$, TDI focal score, and SGRQ total score at 12 and 24 weeks. In the absence of 12- and 24-week data, data within a 2-week range for each time point of interest were allowed (ie, between 10 and 14 weeks for the 12-week time point and between 22 and 26 weeks for the 6-month time point). Differences between the least square mean at follow-up or the change from baseline for the active treatment versus the comparator were used for the network analysis. To be included in the network, outcomes had to be reported for each treatment group in a clear manner to allow reliable estimation of the treatment differences and their associated standard errors.

Rates of exacerbation were compared between the treatment groups at the end of trial follow-up. To be included in the network, this outcome had to be reported as the number of events of exacerbation with the total patient years of follow-up. If such event rates were not available, the rates were then calculated as the number of total events divided by the total patient-years which allowed the rates of exacerbations accumulated over differing periods of follow-up to be compared (assuming the risk of exacerbations remained constant over time). Severity of the exacerbation could not be incorporated into the analysis due to lack of granular severity reporting within the trials.

\section{Network meta-analyses}

NMA combines data from several different randomized comparisons of different treatments to deliver an internally consistent set of estimates while respecting the randomization within each trial. This NMA was carried out within a generalized linear model framework with a link function which specified the relationship between the outcome and the model coefficients to be estimated. When an outcome was continuous, such as trough $\mathrm{FEV}_{1}$, the likelihood was modeled as normal. When the outcome was an event rate, such as the per patient-year event rate of exacerbation, the likelihood was modeled as Poisson. ${ }^{25,26}$ Random effect models were utilized for this analysis. The estimation was performed under a Bayesian context, using noninformative prior distributions for parameters. The model was evaluated using the Deviance Information Criterion, a measure which combines model fit and complexity. This analysis was estimated using a Bayesian Markov Chain Monte Carlo model. All analyses were implemented using the statistical software R (v3.2.2; Ross Ihaka and Robert Gentleman, open source) and OpenBUGS (v3.2.3; OpenBUGS Foundation).

\section{Sensitivity analyses}

Because trough $\mathrm{FEV}_{1}$ was the primary efficacy outcome of the majority of the RCTs, sensitivity analyses were conducted for the $\mathrm{FEV}_{1}$ 12- and 24-week outcomes to test the robustness of the NMA results. Specifically, because concomitant medications and COPD severity are potential treatment effect modifiers, the sensitivity analyses included: 1) a subset of trials with no concomitant LAMA usage (all trials which permitted concomitant usage were excluded); 2) a metaregression adjusting for disease severity (adjusting for the percent of patients with severe/very severe COPD); and 3) a meta-regression adjusting for inhaled corticosteroid (ICS) use (adjusting for the percent of patients with ICS use within each trial).

\section{Results Evidence base}

The updated systematic review identified $9^{16,17,20-22,27-30}$ fulltext articles detailing $12 \mathrm{RCTs}$ that met the inclusion criteria (Figure 1). These were pooled with 21 LABA monotherapy RCTs identified in the previous search, ${ }^{15,18,19,31-48}$ resulting in a total of 33 RCTs included in the NMA. A list of included studies and details of the systematic literature search can be found in Figure 1, and the details of each study's own inclusion criteria are listed in Table S1. All studies were doubleblind, multicenter RCTs (Figure 2), ranging from 12 weeks 


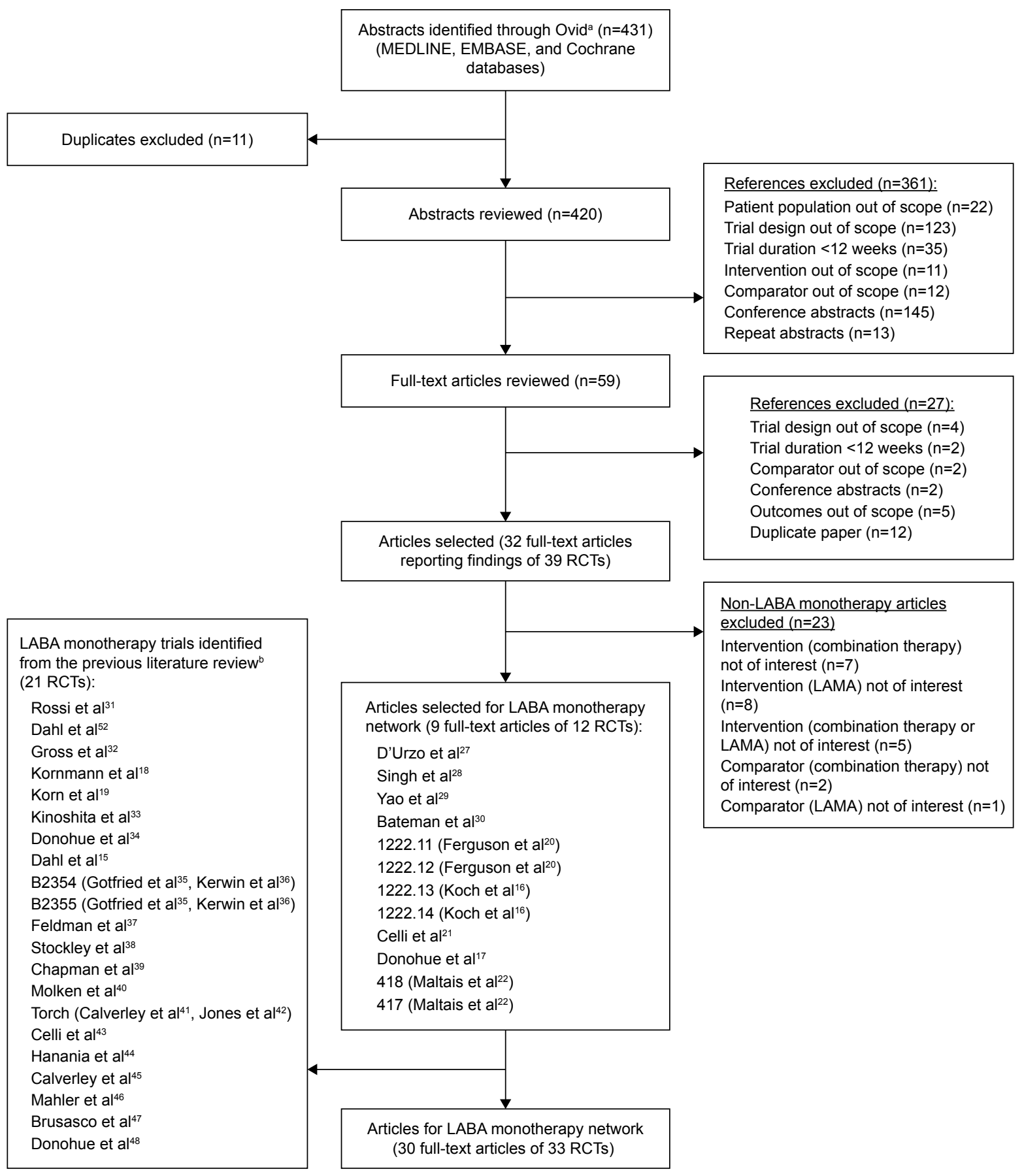

Figure I PRISMA diagram showing selection of LABA monotherapy trials.

Notes: ${ }^{\text {SSearch }}$ was performed for abstracts published between January I, 2013 and March 24, 2015. 'Prior search was performed for abstracts published between 1989 and January I, 2013.

Abbreviations: LABA, long-acting $\beta 2$-agonist; LAMA, long-acting muscarinic antagonist; RCT, randomized controlled trial.

to 3 years in duration. All studies were placebo controlled, with the exception of one head-to-head study which compared the efficacy of indacaterol $150 \mu \mathrm{g}$ OD to salmeterol $50 \mu \mathrm{g}$ BID. ${ }^{19}$ The studies were predominantly conducted in multiple countries simultaneously, although four were limited to the USA ${ }^{32,35,36,44}$ and one was limited to the Netherlands. ${ }^{40}$ The majority of the studies were conducted in patients over the age of 40 with a smoking history of $\geq 10$ pack-years and predicted $\mathrm{FEV}_{1}$ of $\leq 80 \%$. Each trial predominantly enrolled male patients, and the mean age was $>60$ years in all trials. The percentage of ICS use, current smokers, and patients with severe or very severe COPD varied among studies. Patient characteristics of the selected trials are further detailed in Table S2. 


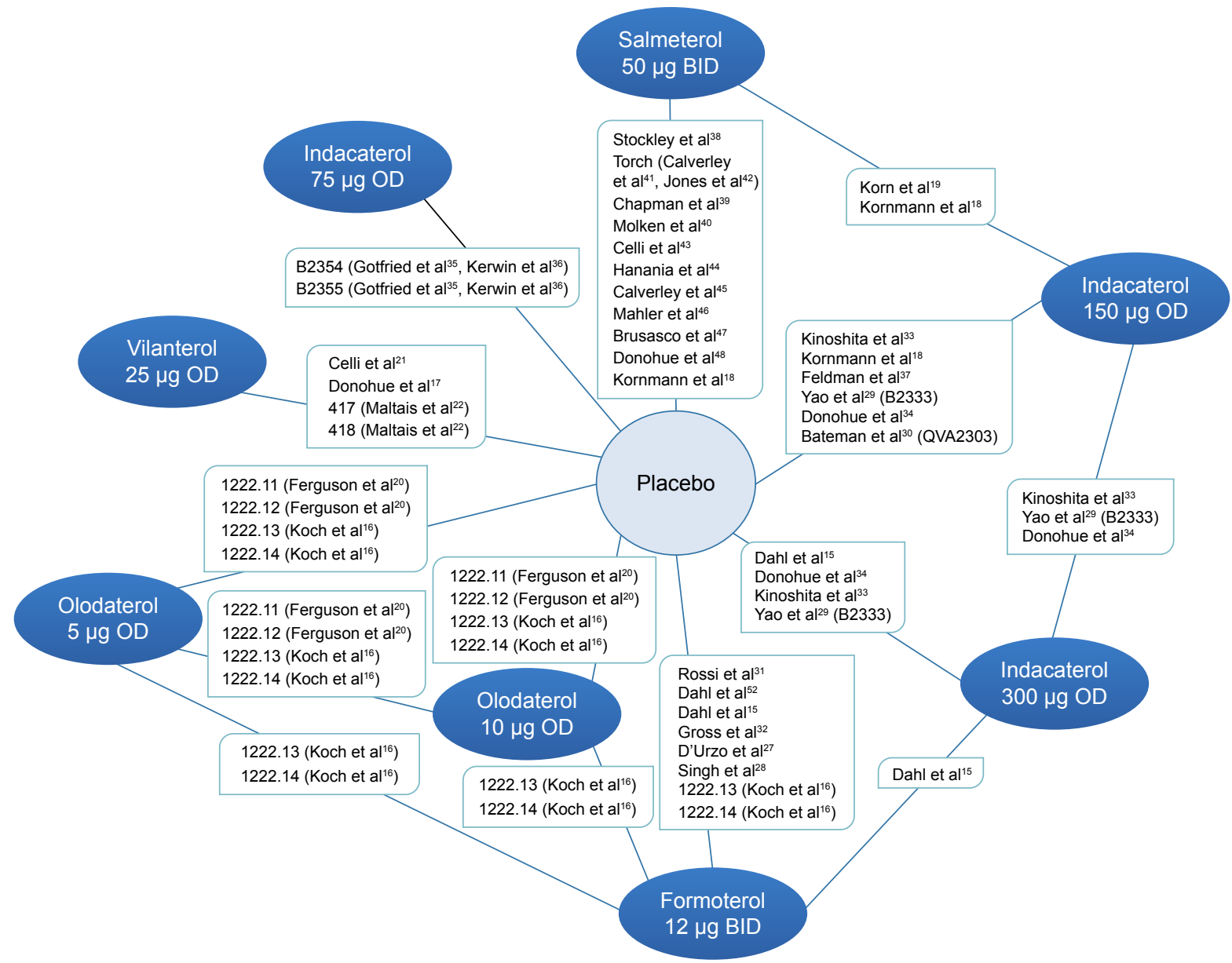

Figure 2 Network diagram of LABA monotherapy trials included in network meta-analysis.

Note: $\mathrm{N}=33$ total randomized controlled trials.

Abbreviations: BID, twice daily; OD, once daily; LABA, long-acting beta agonist.

\section{Network meta-analysis}

The 33 RCTs were synthesized in the NMA; a network diagram of the included studies is detailed in Figure 2. The network for each outcome measure consisted of a subset of the presented network based on the availability of different outcomes within the 33 RCTs.

\section{Trough FEV, at 12 and 24 weeks}

Changes in baseline trough $\mathrm{FEV}_{1}$ at 12 and 24 weeks were reported in a total of 24 and 19 trials, respectively. All interventions were found to be significantly better than placebo in terms of $\mathrm{FEV}_{1}$, at both 12 and 24 weeks.

Relative to placebo at 12 weeks, indacaterol $300 \mu \mathrm{g}$ (difference: $0.167 \mathrm{~L}, 95 \%$ credible interval: [0.151, 0.183]) had the largest difference in change in baseline trough $\mathrm{FEV}_{1}$, followed by indacaterol $150 \mu \mathrm{g}(0.163 \mathrm{~L}[0.148,0.177])$, indacaterol $75 \mu \mathrm{g}(0.129 \mathrm{~L}[0.099,0.157])$, salmeterol $50 \mu \mathrm{g}$ $\operatorname{BID}(0.105 \mathrm{~L}[0.085,0.125])$, vilanterol $25 \mu \mathrm{g}$ OD $(0.098 \mathrm{~L}$ $[0.076,0.120])$, olodaterol $10 \mu \mathrm{g}$ OD $(0.083[0.063,0.103])$, olodaterol $5 \mu \mathrm{g}$ OD $(0.073[0.053,0.092])$, and formoterol $12 \mu \mathrm{g}$ BID (0.071 L [0.057, 0.085]; Figure 3A). Indacaterol $300 \mu \mathrm{g}$ OD and indacaterol $150 \mu \mathrm{g}$ OD were associated with significantly better trough $\mathrm{FEV}_{1}$ compared to indacaterol $75 \mu \mathrm{g}$ OD, salmeterol $50 \mu \mathrm{g}$ BID, vilanterol $25 \mu \mathrm{g}$ OD, olodaterol $10 \mu \mathrm{g}$ OD, olodaterol $5 \mu \mathrm{g}$ OD, and formoterol 12 $\mu \mathrm{g}$ BID, and were not statistically different from each other. Indacaterol $75 \mu \mathrm{g}$ was associated with significantly better trough $\mathrm{FEV}_{1}$ compared to olodaterol $10 \mu \mathrm{g} \mathrm{OD}$, olodaterol 5 $\mu \mathrm{g}$ OD, and formoterol $12 \mu \mathrm{g}$ BID. Salmeterol $50 \mu \mathrm{g}$ BID was associated with significantly better trough $\mathrm{FEV}_{1}$ compared to olodaterol $5 \mu \mathrm{g}$ OD and formoterol $12 \mu \mathrm{g}$ BID. There were no significant differences between indacaterol $75 \mu \mathrm{g}$ OD, salmeterol $50 \mu \mathrm{g}$ BID, and vilanterol $25 \mu \mathrm{g}$ OD.

Relative to placebo at 24 weeks, indacaterol $300 \mu \mathrm{g}$ $(0.162 \mathrm{~L}[0.143,0.181])$ had the largest difference in change in baseline trough $\mathrm{FEV}_{1}$, followed by indacaterol $150 \mu \mathrm{g}$ $(0.147 \mathrm{~L}[0.129,0.164])$, vilanterol $25 \mu \mathrm{g}$ OD $(0.094 \mathrm{~L}$ [0.065, 0.124]), salmeterol $50 \mu \mathrm{g}$ BID (0.082 L [0.066, 0.098]), 
A

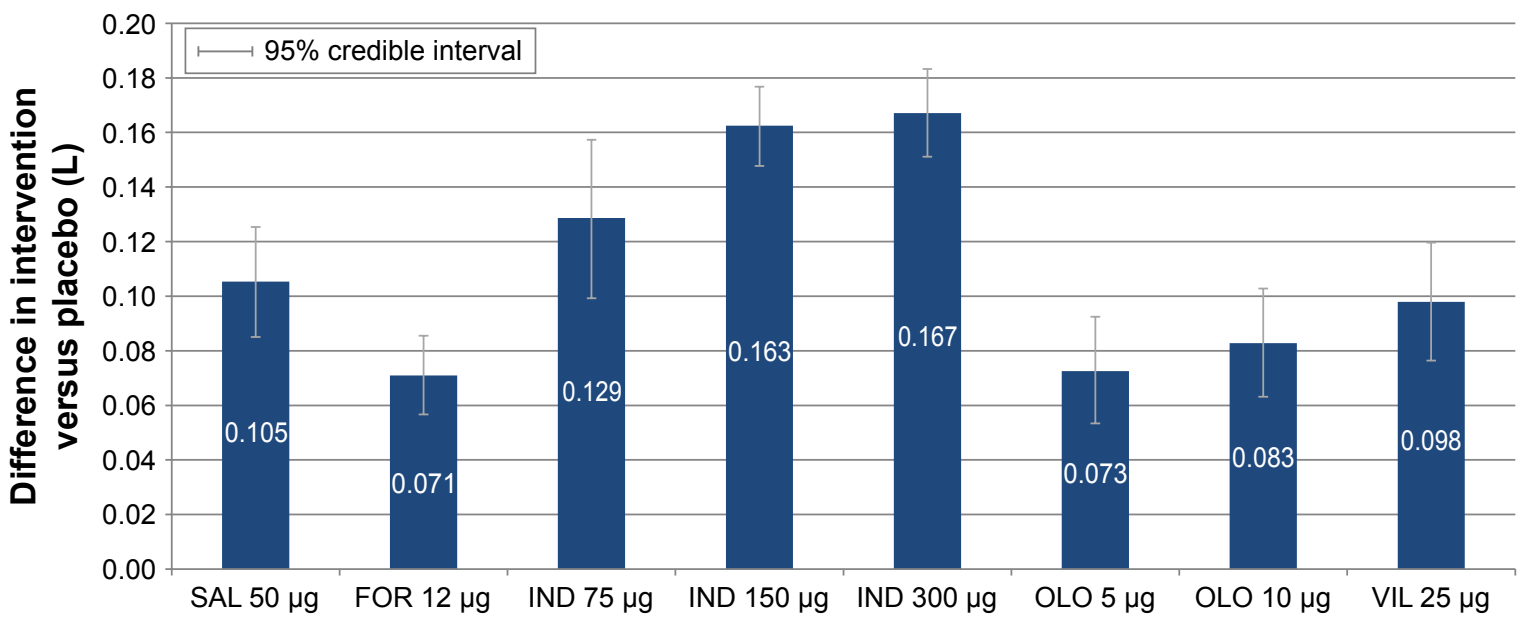

B

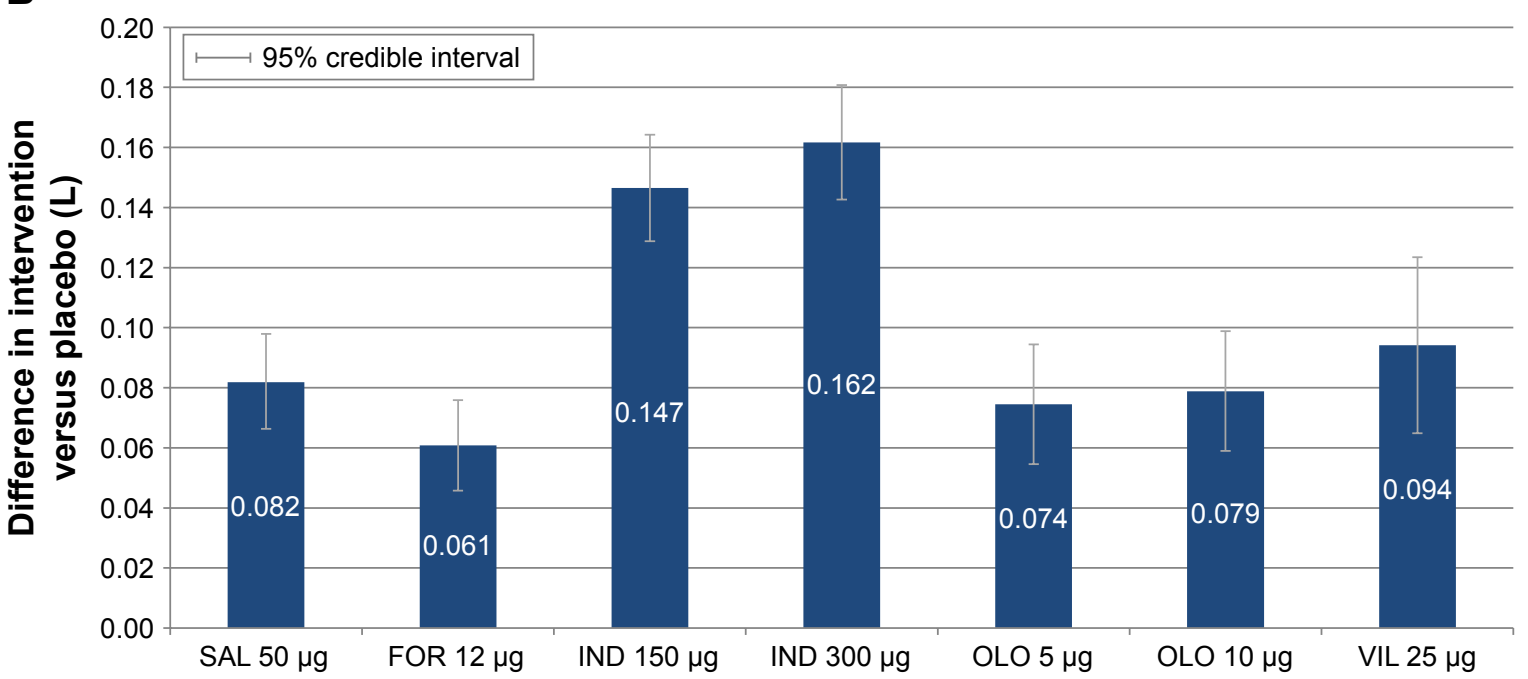

Figure 3 Change from baseline differences in trough FEV $(\mathrm{L})$ for intervention versus placebo at 12 and 24 weeks. (A) Trough FEV , at I2 weeks and (B) trough FEV, at 24 weeks.

Abbreviations: $\mathrm{FEV}_{1}$, forced expiratory volume in I second; FOR, formoterol; IND, indacaterol; OLO, olodaterol; SAL, salmeterol; VIL, vilanterol.

olodaterol $10 \mu \mathrm{g} \mathrm{OD}(0.079 \mathrm{~L}[0.059,0.099])$, olodaterol $5 \mu \mathrm{g}$ OD $(0.074$ [0.055, 0.094]), and formoterol $12 \mu \mathrm{g}$ BID (0.061 [0.046, 0.076]; Figure 3B). Indacaterol $75 \mu \mathrm{g}$ OD was not included in the 24-week analysis. As in the 12-week analysis, indacaterol $300 \mu \mathrm{g}$ OD and indacaterol $150 \mu \mathrm{g}$ OD were associated with significantly better trough $\mathrm{FEV}_{1}$ compared to vilanterol $25 \mu \mathrm{g}$ OD, salmeterol $50 \mu \mathrm{g}$ BID, olodaterol 10 $\mu \mathrm{g}$ OD, olodaterol $5 \mu \mathrm{g}$ OD, and formoterol $12 \mu \mathrm{g}$ BID, and were not statistically different from each other (Table 2). In addition, vilanterol $25 \mu \mathrm{g}$ OD had significantly higher mean trough $\mathrm{FEV}_{1}$ than formoterol $12 \mu \mathrm{g}$ BID. No other significant differences were observed at 24 weeks.

\section{TDI focal score at 12 and 24 weeks}

Changes in baseline mean TDI focal scores at 12 and 24 weeks were reported in 14 and 15 trials, respectively. At 12 and
24 weeks, all interventions were found to be significantly better than placebo. Relative to placebo at 12 weeks, indacaterol 300, 150, and $75 \mu \mathrm{g}$ OD (1.171 [0.906, 1.401], 1.051 $[0.826,1.291]$, and $0.831[0.330,1.336]$, respectively) had the highest difference in TDI focal scores at 12 weeks, followed by olodaterol $10 \mu \mathrm{g}$ OD $(0.734$ [0.278, 1.166]), vilanterol $25 \mu \mathrm{g}$ OD $(0.665[0.284,1.054])$, olodaterol $5 \mu \mathrm{g}$ OD $(0.629$ [0.187, 1.058]), formoterol $12 \mu \mathrm{g} \operatorname{BID}(0.618$ [0.281, 0.925]), and salmeterol $50 \mu \mathrm{g}$ BID (0.555 [0.246, 0.887]; Figure 4A). Indacaterol $300 \mu \mathrm{g}$ OD and indacaterol $150 \mu \mathrm{g}$ OD were associated with significantly higher mean TDI focal score compared to salmeterol $50 \mu \mathrm{g}$ BID and formoterol $12 \mu \mathrm{g}$ BID. Indacaterol $300 \mu \mathrm{g}$ OD was also associated with significantly higher mean TDI focal score compared to olodaterol $5 \mu \mathrm{g}$ OD and vilanterol $25 \mu \mathrm{g}$ OD (Table 3). No other significant differences were observed at 12 weeks. 


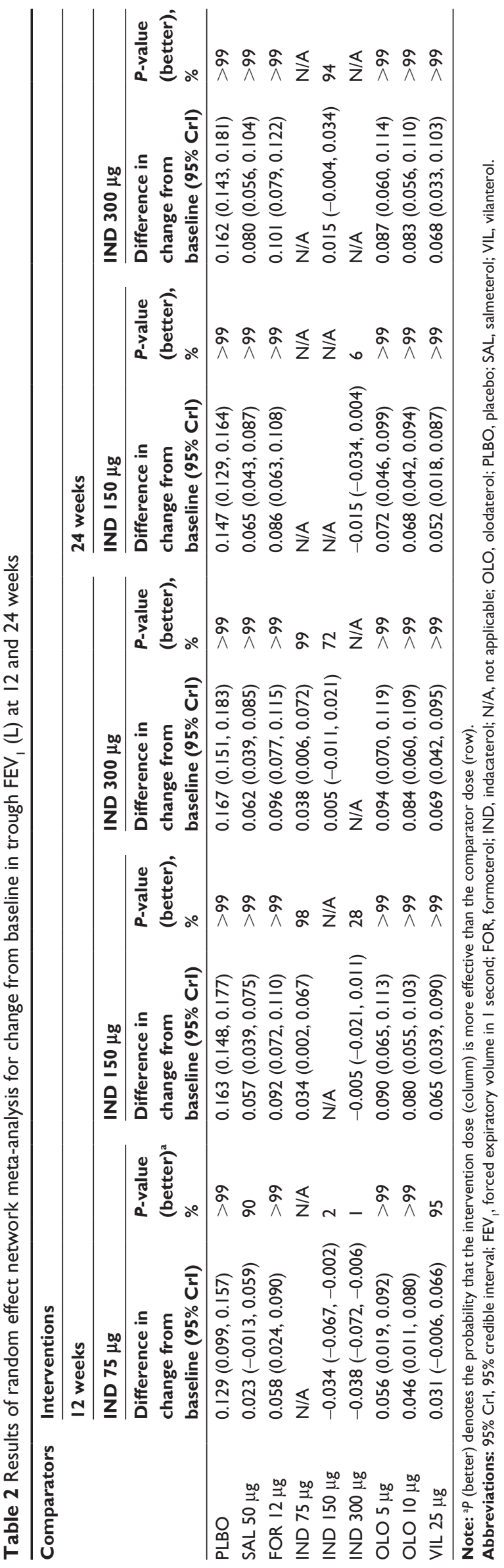

Relative to placebo at 24 weeks, indacaterol $300 \mu \mathrm{g}$ OD $(1.184[0.942,1.433])$ had the highest difference in TDI focal scores at 24 weeks, followed by indacaterol $150 \mu \mathrm{g}$ OD (0.894 [0.653, 1.139]), salmeterol $50 \mu \mathrm{g}$ BID (0.696 [0.423, $0.965])$, vilanterol $25 \mu \mathrm{g} \mathrm{OD}(0.693$ [0.297, 1.093]), formoterol $12 \mu \mathrm{g}$ BID $(0.594$ [0.359, 0.838]), olodaterol $5 \mu \mathrm{g}$ OD $(0.556[0.143,0.975)$, and olodaterol $10 \mu \mathrm{g}$ OD (0.501 [0.097, 0.920]; Figure 4B). Indacaterol $75 \mu \mathrm{g}$ OD was not included in the 24-week analysis. Indacaterol $300 \mu \mathrm{g}$ OD was associated with a significantly higher mean TDI focal score compared to all other LABAs (including indacaterol $150 \mu \mathrm{g}$ OD; Table 3). No other significant differences were observed at 24 weeks.

\section{SGRQ total score at 12 and 24 weeks}

Changes from baseline in SGRQ total score at weeks 12 and 24 were reported in a total of 14 and 16 trials, respectively. At 12 and 24 weeks, all interventions were found to be significantly better than placebo. No significant differences were noted at 12 or 24 weeks between the different LABAs, except that indacaterol $150 \mu \mathrm{g}$ was significantly better than salmeterol $50 \mu \mathrm{g}$ BID $(-1.776[-3.430,-0.023])$ at week 24 (Table 4).

Relative to placebo, the numerically best SGRQ scores at 12 weeks belonged to (in order) olodaterol $10 \mu \mathrm{g}$ OD $(-4.144[-6.089,-2.161])$, indacaterol $150 \mu \mathrm{g}$ $(-4.022[-5.096,-2.962])$, indacaterol $300 \mu \mathrm{g}(-3.704$ $[-4.922,-2.501])$, and indacaterol $75 \mu \mathrm{g}$ OD $(-3.691$ $[-5.825,-1.509])$, followed by formoterol $12 \mu \mathrm{g}$ BID $(-3.150[-4.464,-1.890])$, olodaterol $5 \mu \mathrm{g}$ OD $(-3.047$ $[-5.014,-1.107])$, and salmeterol $50 \mu \mathrm{g}$ BID $(-2.710$ $[-4.463,-0.935])$. For 24 weeks, the best scores belonged to olodaterol $10 \mu \mathrm{g}$ OD $(-3.589[-5.704,-1.429])$, indacaterol $150 \mu \mathrm{g}$ OD $(-3.155[-4.504,-1.752])$, and vilanterol $25 \mu \mathrm{g}$ OD $(-2.906[-5.042,-0.769])$, followed by indacaterol $300 \mu \mathrm{g}$ OD $(-2.843[-4.321,-1.407])$, formoterol $12 \mu \mathrm{g}$ BID $(-1.401[-2.694,-0.113])$, and salmeterol $50 \mu \mathrm{g} \operatorname{BID}(-1.379$ $[-2.559,-0.286]$; Figure 5). Vilanterol $25 \mu \mathrm{g}$ OD was not included in the 12-week analysis, and indacaterol $75 \mu \mathrm{g}$ OD was not included in the 24-week analysis.

\section{Exacerbation rate}

A total of 14 trials that reported the exacerbation rate were included in the evidence network including salmeterol $50 \mu \mathrm{g}$ $\mathrm{BID}$, formoterol $12 \mu \mathrm{g} \mathrm{BID}$, indacaterol $150 \mu \mathrm{g}$ OD, indacaterol $300 \mu \mathrm{g}$ OD, olodaterol $5 \mu \mathrm{g}$ OD, olodaterol $10 \mu \mathrm{g}$ OD, and placebo. The exacerbation rates were significantly lower for salmeterol $50 \mu \mathrm{g} \mathrm{BID}$, indacaterol $150 \mu \mathrm{g}$ OD, and indacaterol $300 \mu \mathrm{g}$ OD, compared with placebo. In addition, indacaterol $150 \mu \mathrm{g}$ OD was significantly better than olodaterol 
A

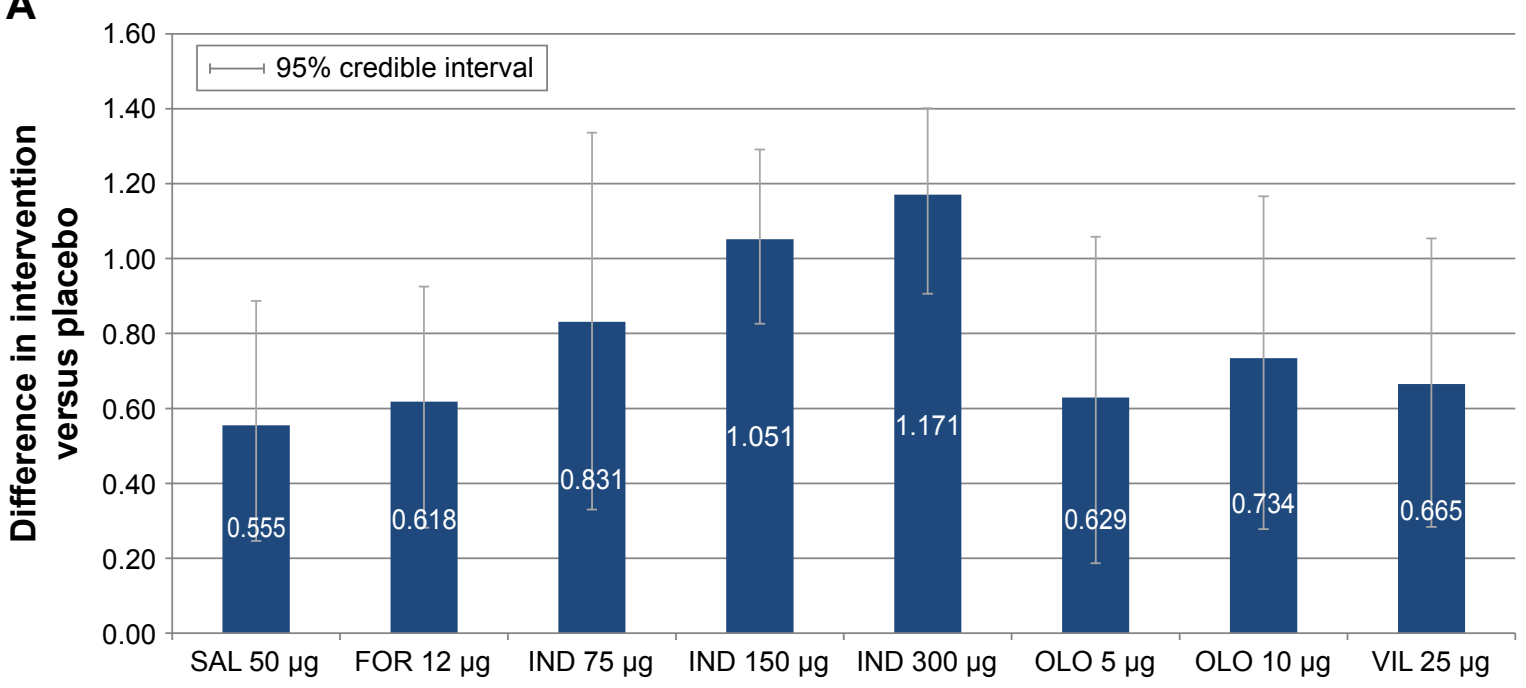

B

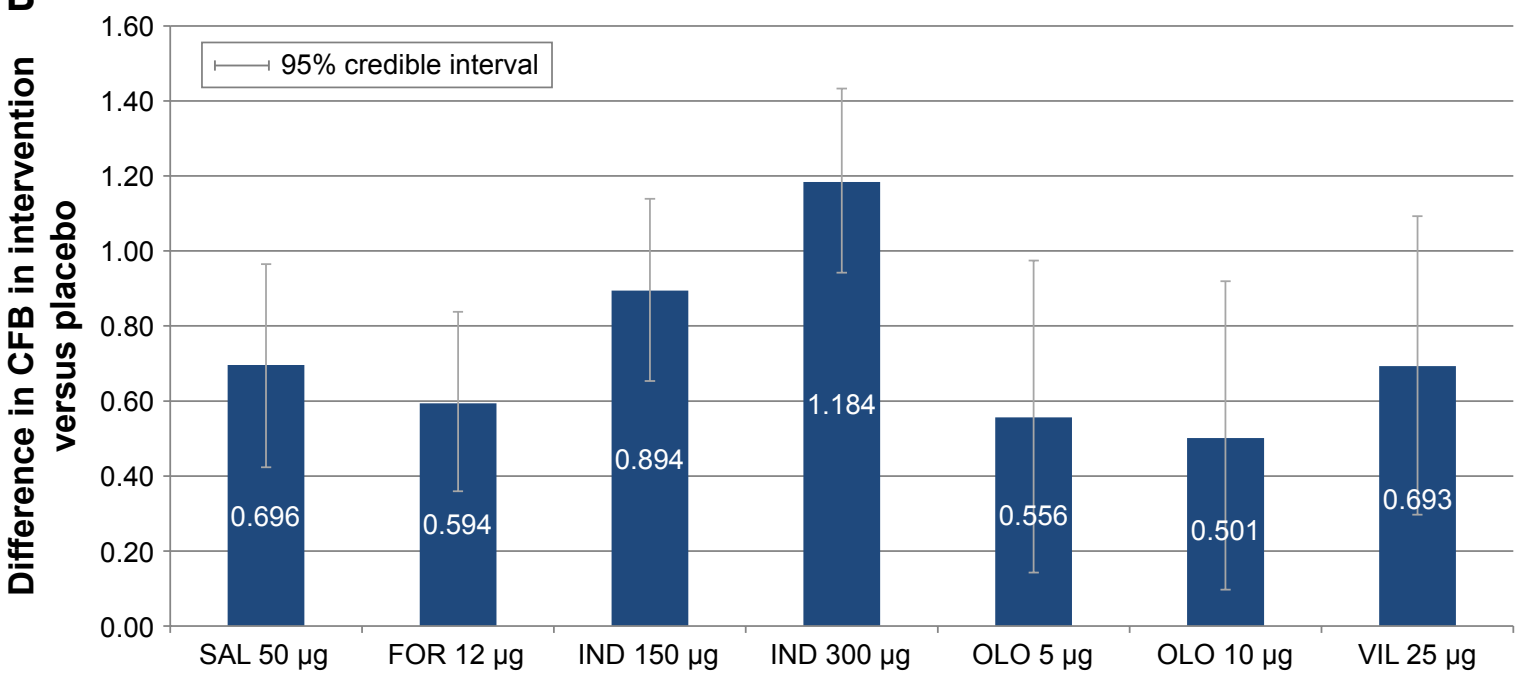

Figure 4 Difference in change from baseline TDI focal score of intervention versus placebo at I2 and 24 weeks. (A) TDI focal score at I2 weeks and (B) TDI focal score at 24 weeks.

Abbreviations: FOR, formoterol; IND, indacaterol; OLO, olodaterol; SAL, salmeterol; TDI, transition dyspnea index; VIL, vilanterol; CFB, change from baseline.

$5 \mu \mathrm{g}$ OD $(0.773[0.590,0.991])$ and olodaterol $10 \mu \mathrm{g}$ OD (0.737 [0.565, 0.939]; Table 5 and Figure 6).

\section{Sensitivity analysis for trough FEV,}

A summary of the NMA results for trough $\mathrm{FEV}_{1}$ after adjusting for female percentage, disease severity, ICS use, and the subgroup with no concomitant LAMA use at 12 and 24 weeks is presented in Figure 7. All the changes were minimal, ranging from -0.005 to $0.004 \mathrm{~L}$ for week 12 outcomes and from -0.006 to $0.012 \mathrm{~L}$ for week 24 outcomes, illustrating that the NMA results were robust.

\section{Discussion}

This study is the first NMA to analyze the comparative efficacy of all currently available LABAs, including the newer agents for the treatment of moderate to severe COPD. Thus, this study provides the most up-to-date understanding of the treatment landscape for COPD in terms of LABA monotherapies as well as the most complete comparative analysis of effective treatment options and dosages in terms of efficacy outcomes: FEV ${ }_{1}$, TDI focal score, SGRQ, and exacerbation rate. The results indicate that indacaterol was the most effective LABA monotherapy for the treatment of COPD, similar to the findings of earlier studies comparing LABA efficacy. ${ }^{23,24}$

Specifically, indacaterol $150 \mu \mathrm{g}$ OD and indacaterol $300 \mu \mathrm{g}$ OD were associated with significant improvement in 12- and 24-week trough $\mathrm{FEV}_{1}$ compared to all other LABAs, and indacaterol $75 \mu \mathrm{g}$ OD was associated with significant improvement in trough $\mathrm{FEV}_{1}$ at week 12 


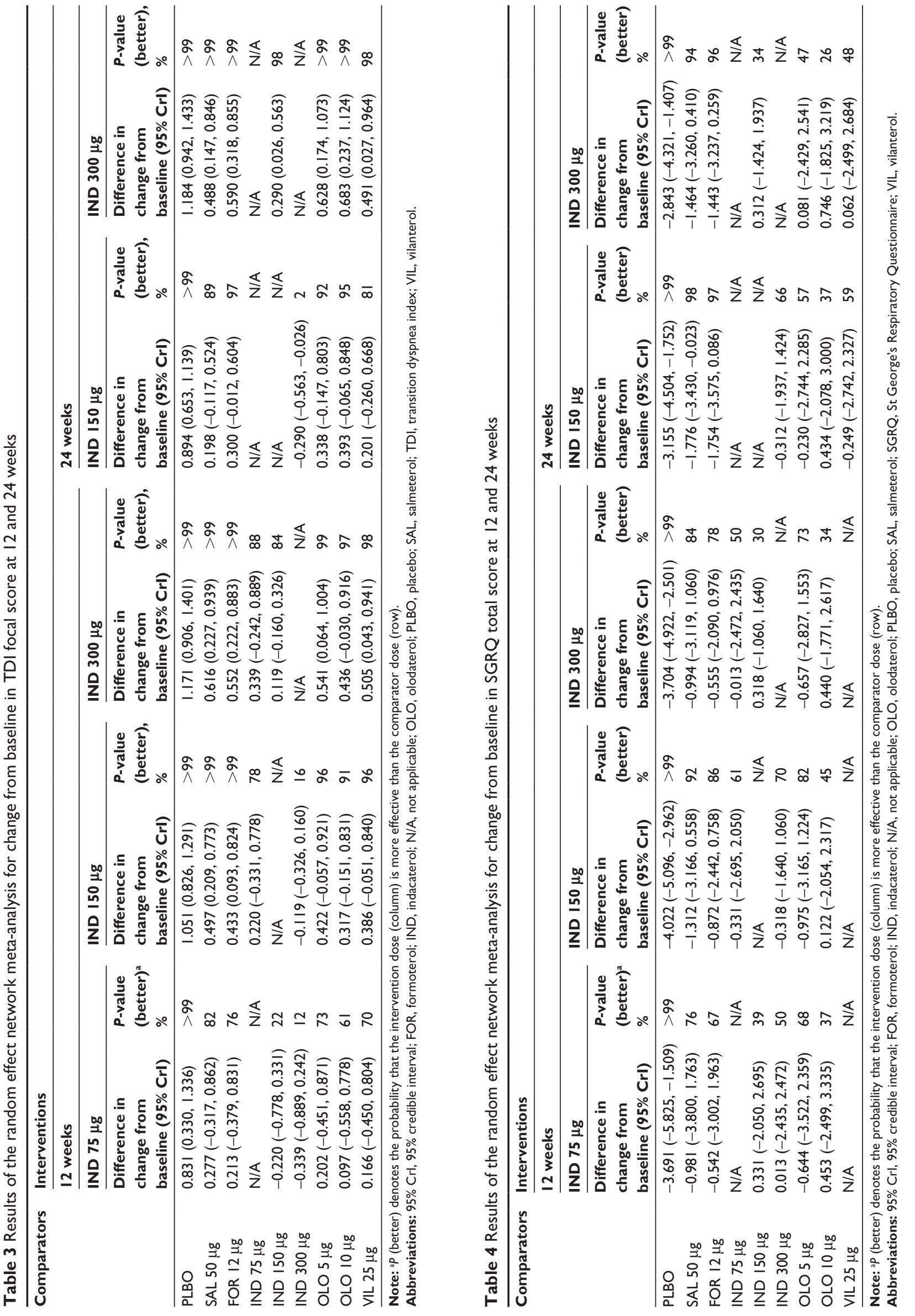




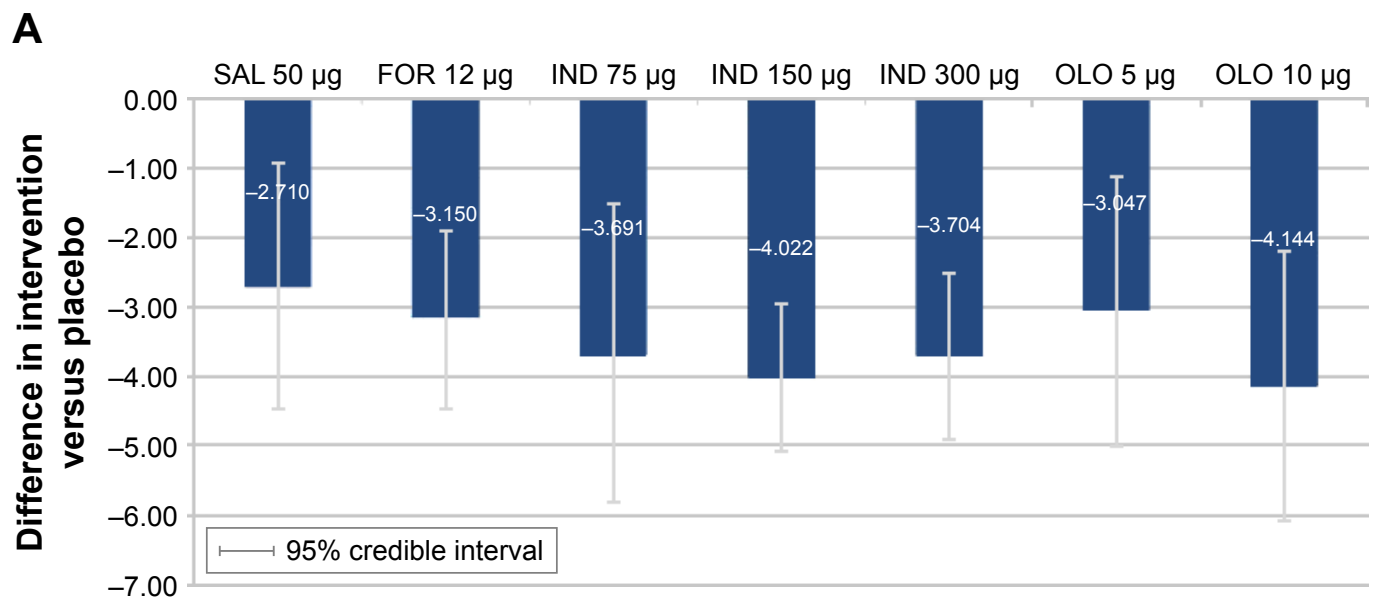

B

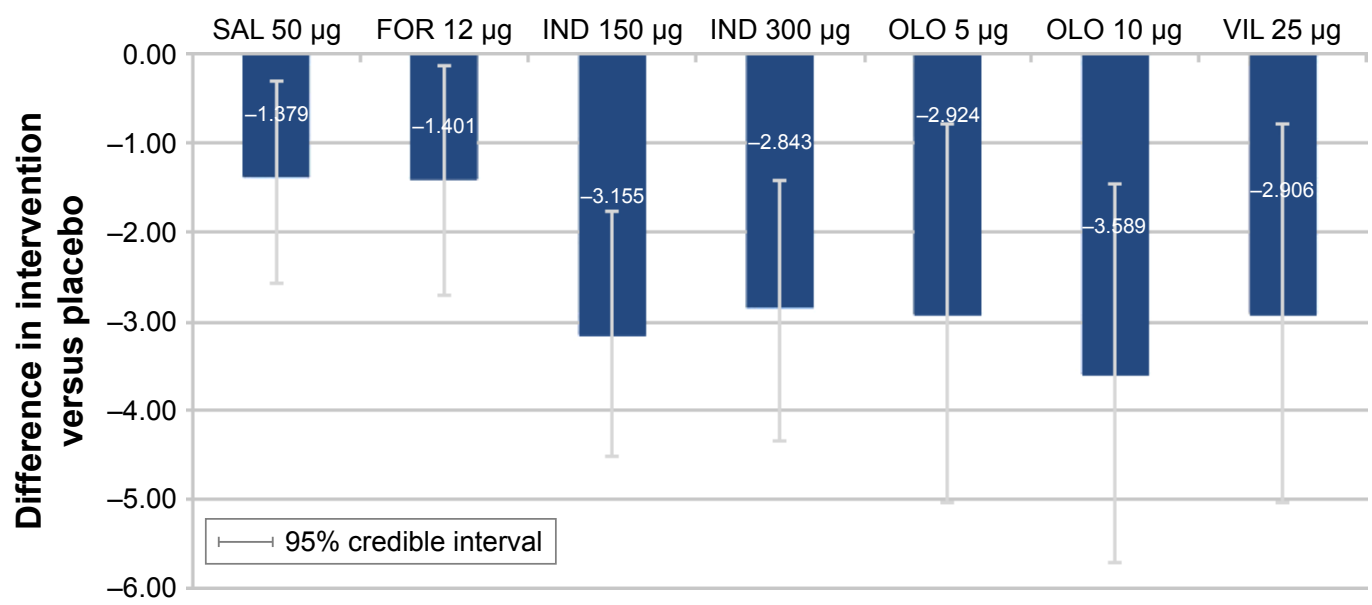

Figure 5 Change from baseline difference in SGRQ total score for intervention versus placebo at I2 and 24 weeks. (A) SGRQ total score at I2 weeks and (B) SGRQ total score at 24 weeks.

Abbreviations: FOR, formoterol; IND, indacaterol; OLO, olodaterol; PLBO, placebo; SAL, salmeterol; SGRQ, St George's Respiratory Questionnaire; VIL, vilanterol.

compared to formoterol and olodaterol (both 5 and $10 \mu \mathrm{g}$ doses). In addition, indacaterol, $300 \mu \mathrm{g}$ in particular, showed statistical superiority over other LABAs in TDI score, and indacaterol $150 \mu \mathrm{g}$ showed statistical superiority over olodaterol $5 \mu \mathrm{g}$ and olodaterol $10 \mu \mathrm{g}$ OD in exacerbation rates. Olodaterol $10 \mu \mathrm{g}$ OD showed numerical superiority in SGRQ scores at 12 and 24 weeks, although the results were not statistically different from the other LABAs.

The outcomes compared in this meta-analysis each have valid thresholds for clinically relevant differences versus placebo. For example, for $\mathrm{FEV}_{1}$, a widely accepted threshold, is a change of $100 \mathrm{~mL}$ from baseline; for TDI focal

Table 5 Results of random effect network meta-analysis for exacerbation rate

\begin{tabular}{|c|c|c|c|c|}
\hline \multirow[t]{3}{*}{ Comparators } & \multicolumn{4}{|l|}{ Interventions } \\
\hline & \multicolumn{2}{|l|}{ IND I50 $\mu \mathrm{g}$} & \multicolumn{2}{|l|}{ IND $300 \mu \mathrm{g}$} \\
\hline & Rate ratio $(95 \% \mathrm{Crl})$ & $\begin{array}{l}P \text {-value } \\
\text { (better) \%a }\end{array}$ & Rate ratio $(95 \%$ Crl) & $\begin{array}{l}P \text {-value } \\
\text { (better) \%a }\end{array}$ \\
\hline PLBO & $0.729(0.607,0.866)$ & $>99$ & $0.817(0.692,0.959)$ & $>99$ \\
\hline SAL $50 \mu g$ & $0.895(0.737,1.089)$ & 88 & $1.004(0.834,1.220)$ & 52 \\
\hline FOR $12 \mu \mathrm{g}$ & $0.845(0.657,1.072)$ & 93 & $0.945(0.760$, I.I59) & 73 \\
\hline IND I50 $\mu \mathrm{g}$ & $\mathrm{N} / \mathrm{A}$ & $\mathrm{N} / \mathrm{A}$ & I.I $28(0.909$, I.378) & 13 \\
\hline IND $300 \mu \mathrm{g}$ & $0.897(0.726,1.100)$ & 87 & $N / A$ & $\mathrm{~N} / \mathrm{A}$ \\
\hline OLO $5 \mu \mathrm{g}$ & $0.773(0.590,0.991)$ & 98 & $0.865(0.674,1.094)$ & 89 \\
\hline OLO $10 \mu \mathrm{g}$ & $0.737(0.565,0.939)$ & $>99$ & $0.826(0.645,1.035)$ & 96 \\
\hline
\end{tabular}

Note: ${ }^{a}$ (better) denotes the probability that the intervention dose (column) is more effective than the comparator dose (row).

Abbreviations: $95 \% \mathrm{Crl}$, 95\% credible interval; FOR, formoterol; IND, indacaterol; N/A, not applicable; OLO, olodaterol; PLBO, placebo; SAL, salmeterol. 


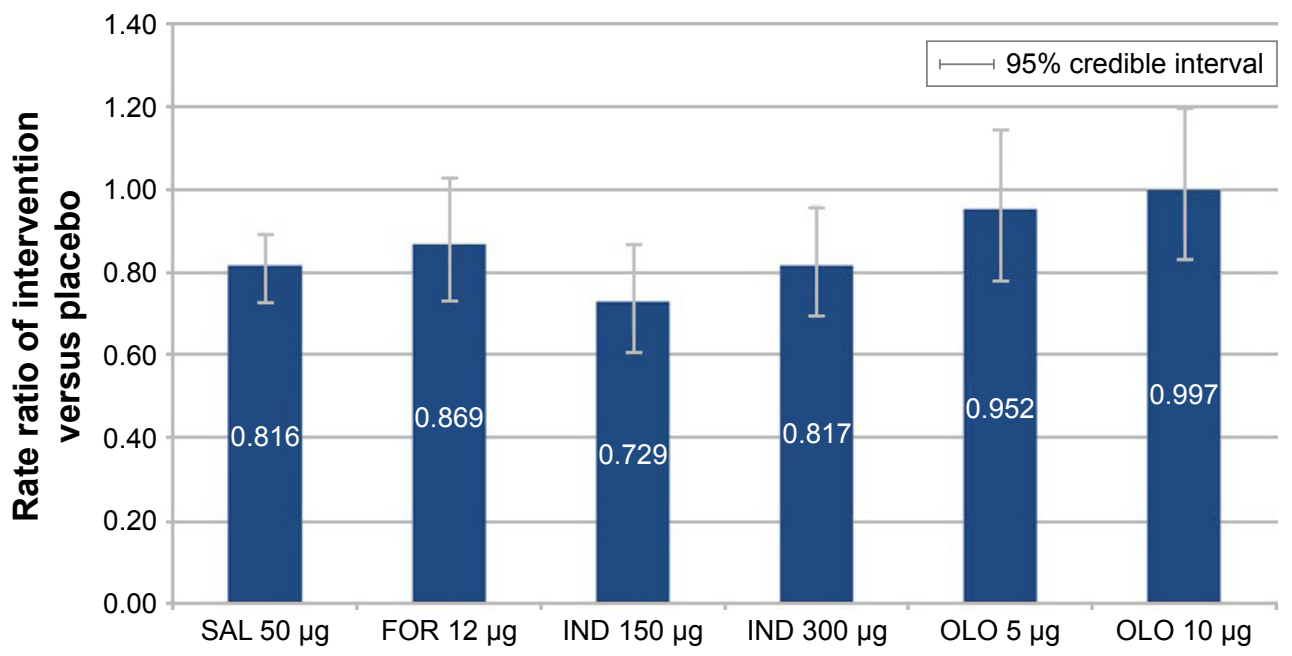

Figure 6 Exacerbation rate (rate ratio) of intervention versus placebo.

Abbreviations: FOR, formoterol; IND, indacaterol; OLO, olodaterol; SAL, salmeterol.

score, $a \geq 1$ unit score reduction; for SGRQ total score, a reduction of 4 units; and for exacerbation rate, an annual rate reduction of $20 \% .{ }^{49}$ These outcomes were used for the determination of efficacy against placebo in respective clinical trials; however, the validity of using these thresholds for post hoc active-arm comparisons has not been empirically evaluated. Thus, NMAs such as the current analysis are useful for comparing active treatments by testing for statistically significant differences between treatment outcomes after showing clinically meaningful efficacy against placebo. Future prospective studies evaluating the thresholds for clinically meaningful differences between active treatments in COPD therapy trials are needed.

The results of this study add to and update the pre-existing literature on the comparative efficacy of LABAs in the treatment of COPD, while coming to similar conclusions as previous studies about the efficacy of indacaterol. For example, a 2013 NMA on the comparative efficacy of long-acting bronchodilators for COPD found that indacaterol was associated with higher trough $\mathrm{FEV}_{1}$ and superior improvement in SGRQ score over comparative LABAs. ${ }^{23}$ In addition, a 2012 comparative effectiveness study evaluated indacaterol for COPD versus placebo, formoterol, and salmeterol in RCTs using the outcomes trough $\mathrm{FEV}_{1}, \mathrm{SGRQ}$, and TDI total scores. It found that indacaterol was as good as or superior to these bronchodilators in all the outcomes measured, and that indacaterol $300 \mu \mathrm{g}$ resulted in the best overall efficacy. ${ }^{50}$ A 2014 systematic review compared efficacy outcomes $\left(\mathrm{FEV}_{1}, \mathrm{SGRQ}\right.$ and TDI scores, exacerbations, and use of rescue medication at 12 weeks) for olodaterol and indacaterol and determined that these drugs had similar efficacy. ${ }^{24}$ However, a comment published later in 2014 noted that the study suffered from several limitations including a restricted search date resulting in exclusion of relevant clinical trials, study design heterogeneity, and reliance on data from other NMAs rather than primary data within RCTs. ${ }^{51}$

In the current analysis, only trials of the inhalation powder form of formoterol were included, in order to maintain consistency with the delivery device of the other comparators. However, nebulized formoterol may be beneficial for patients who are unable to use inhalation powder for reasons including frailty, arthritis, visual impairment, compromised mental capacity, exacerbation, difficulty using an inhaler, or inadequate hand/breath coordination.

Important differences may exist between real-world practice and clinical trial populations, such as training for the use of inhalers, adherence to treatment, and routine medical care, all of which may limit the applicability of the current results. Some limitations inherent to NMAs apply to the results of this study. For example, although the trials included in the NMA were of good caliber, the validity of the current findings depends on the quality, biases, and study and patient characteristic reporting consistency of the included RCTs. Some variation existed in their inclusion criteria regarding the concomitant use of LABA and ICSs, smoking history, age, the severity of COPD, and exacerbation history. Though sensitivity analyses have been conducted for our main outcome $\mathrm{FEV}_{1}$, meta-regression analyses of studylevel data can be prone to ecological bias (ie, the association between the study-level effect patient characteristics and treatment effects may not reflect the individual-level effect modification of a covariate). Thus, there is a risk of residual confounding bias. Since there was only a single head-to-head trial, the ability to check the consistency of the direct and 

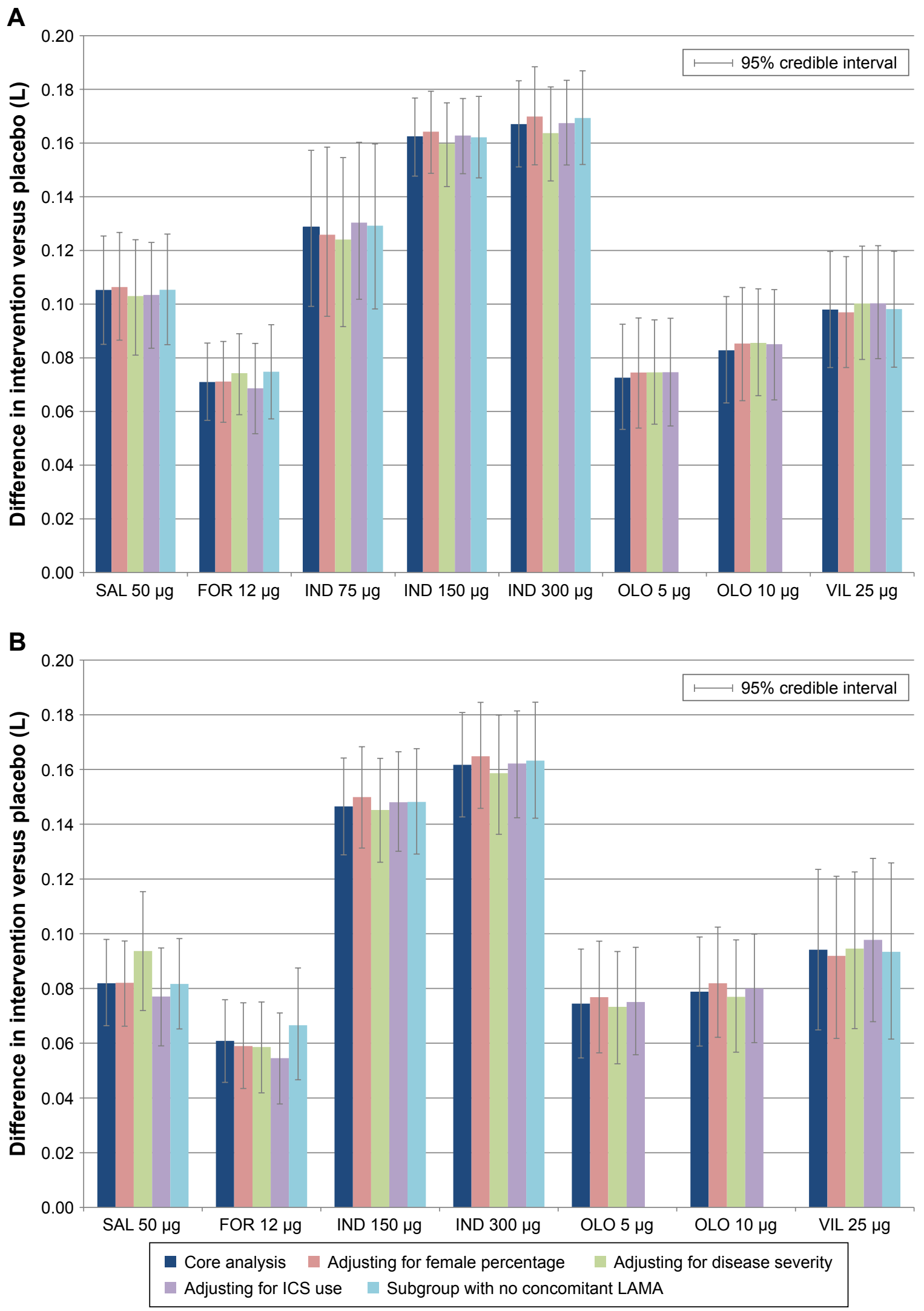

Figure 7 Sensitivity analysis for change from baseline in trough FEV,$(\mathrm{L})$. (A) Trough FEV, at 12 weeks and (B) trough FEV, at 24 weeks.

Abbreviations: $\mathrm{FEV}_{1}$, forced expiratory volume in I second; FOR, formoterol; ICS, inhaled corticosteroid; IND, indacaterol; LAMA, long-acting muscarinic antagonist; OLO, olodaterol; SAL, salmeterol; VIL, vilanterol. 
indirect evidence was limited. However, in this head-to-head trial, indacaterol $150 \mu \mathrm{g}$ was associated with a $0.06 \mathrm{~L}$ higher $\mathrm{FEV}_{1}$ compared to salmeterol $50 \mu \mathrm{g},{ }^{19}$ which is consistent with the $0.057 \mathrm{~L}$ estimated in this analysis. In addition, other outcomes, which are important in the measurement of COPD treatment efficacy and safety and played an essential role in treatment decisions, such as the use of rescue treatments and the severity of exacerbations, were not assessed in this study. Future studies are warranted to further evaluate these outcomes among different treatment options for COPD patients. Lastly, exacerbations were expected to be defined differently among the included studies, and the NMA results might be subject to those inconsistencies, if any. Because the number of studies that contained that study outcome (exacerbations) was small, no subgroup analysis was conducted in this study. Future research may be needed to conduct subgroup analysis among studies with consistent criteria and definitions, when there are sufficient studies.

\section{Conclusion}

In conclusion, indacaterol $300 \mu \mathrm{g} \mathrm{OD}$, followed by $150 \mu \mathrm{g}$ OD, and $75 \mu \mathrm{g}$ OD, were the most effective LABA monotherapies for COPD in terms of trough $\mathrm{FEV}_{1}$ and TDI focal scores.

\section{Acknowledgments}

Medical writing assistance was provided by Shelley Batts, $\mathrm{PhD}$, an employee of Analysis Group, Inc., with financial support from Novartis. We would like to thank Jenny Guo of Analysis Group for helping with part of the data analysis and Noelle Thew of Analysis Group for helping audit the manuscript. Funding for this research was provided by Novartis.

\section{Author contributions}

All authors had full access to all of the data in the study and take responsibility for the integrity of the data and accuracy of the data analysis. All authors contributed substantially to the study design, data analysis and interpretation, and the writing of the manuscript. The study sponsor was involved in all stages of the study research and manuscript preparation, but all authors participated in the design of the study and contributed to the manuscript development. Data were collected by Analysis Group and analyzed and interpreted in collaboration with all other authors. All the authors vouch for the accuracy and completeness of the data reported and the adherence of the study to the protocol, and all the authors made the decision to submit the manuscript for publication.

\section{Disclosure}

J-BG, PG, PA, and DLK are employees of Novartis and own stock/stock options. KAB, EXD, and JES are employees of Analysis Group Inc., which has received consultancy fees from Novartis. JFD is a member of the Data Safety Monitoring Board for Novartis, AstraZeneca, Gilead, CSA Medical, and Insmed, and is a consultant to AstraZeneca, Sunovion, and GlaxoSmithKline. The authors report no other conflicts of interest in this work.

\section{References}

1. Global Strategy for the Diagnosis, Management and Prevention of COPD, Global Initiative for Chronic Obstructive Lung Disease (GOLD) 2016. (updated January 2016). Available from: http://www. goldcopd.org/. Accessed April 7, 2016.

2. Vos T, Flaxman AD, Naghavi M, et al. Years lived with disability (YLDs) for 1,160 sequelae of 289 diseases and injuries 1990-2010: a systematic analysis for the Global Burden of Disease Study 2010. Lancet. 2012;380(9859):2163-2196.

3. Davis RM, Novotny TE. The epidemiology of cigarette smoking and its impact on chronic obstructive pulmonary disease. Am Rev Respir Dis. 1989;140(3 Pt 2):S82-S84.

4. Kojima S, Sakakibara H, Motani S, et al. Incidence of chronic obstructive pulmonary disease, and the relationship between age and smoking in a Japanese population. J Epidemiol. 2007;17(2):54-60.

5. Schikowski T, Sugiri D, Ranft U, et al. Long-term air pollution exposure and living close to busy roads are associated with COPD in women. Respir Res. 2005;6:152.

6. WHO. Chronic obstructive pulmonary disease (COPD); 2016. Available from: http://www.who.int/mediacentre/factsheets/fs315/en/. Accessed April 4, 2016.

7. Celedon JC, Lange C, Raby BA, et al. The transforming growth factorbeta1 (TGFB1) gene is associated with chronic obstructive pulmonary disease (COPD). Hum Mol Genet. 2004;13(15):1649-1656.

8. Keatings VM, Cave SJ, Henry MJ, et al. A polymorphism in the tumor necrosis factor-alpha gene promoter region may predispose to a poor prognosis in COPD. Chest. 2000;118(4):971-975.

9. Anzueto A, Sethi S, Martinez FJ. Exacerbations of chronic obstructive pulmonary disease. Proc Am Thorac Soc. 2007;4(7):554-564.

10. Lopez-Campos JL, Tan W, Soriano JB. Global burden of COPD. Respirology. 2016;21(4):14-23.

11. WHO. Household air pollution and health, Fact sheet \#292; 2016. Available from: http://www.who.int/mediacentre/factsheets/fs292/en/. Accessed April 4, 2016.

12. NIH-NHLB. Morbidity \& mortality: 2012 chart book on cardiovascular, lung, and blood diseases; 2012. Available from: http://www.nhlbi.nih. gov/resources/docs/2012_ChartBook_508.pdf. Accessed April 7, 2016.

13. FDA Drug Safety Communication: new safety requirements for long-acting inhaled asthma medications called Long-Acting BetaAgonists (LABAs); 2010. Available from: http://www.fda.gov/Drugs/ DrugSafety/PostmarketDrugSafetyInformationforPatientsandProviders/ucm200776.htm. Accessed September 27, 2016

14. Cazzola M, Page C. Long-acting bronchodilators in COPD: where are we now and where are we going? Breathe. 2014;10(2):110-120.

15. Dahl R, Chung KF, Buhl R, et al. Efficacy of a new once-daily longacting inhaled beta2-agonist indacaterol versus twice-daily formoterol in COPD. Thorax. 2010;65(6):473-479.

16. Koch A, Pizzichini E, Hamilton A, et al. Lung function efficacy and symptomatic benefit of olodaterol once daily delivered via Respimat ${ }^{\text {B }}$ versus placebo and formoterol twice daily in patients with GOLD 2-4 COPD: results from two replicate 48-week studies. Int J Chron Obstruct Pulmon Dis. 2014;9:697-714. 
17. Donohue JF, Maleki-Yazdi MR, Kilbride S, Mehta R, Kalberg C, Church A. Efficacy and safety of once-daily umeclidinium/vilanterol 62.5/25 mcg in COPD. Respir Med. 2013;107(10):1538-1546.

18. Kornmann O, Dahl R, Centanni S, et al; INLIGHT-2 (Indacaterol Efficacy Evaluation Using 150- $\mu$ g Doses with COPD Patients) study investigators. Once-daily indacaterol versus twice-daily salmeterol for COPD: a placebo-controlled comparison. Eur Respir J. 2011;37(2): 273-279.

19. Korn S, Kerwin E, Atis S, Amos C, Owen R, Lassen C; INSIST study group. Indacaterol once-daily provides superior efficacy to salmeterol twice-daily in COPD: a 12-week study. Respir Med. 2011;105(5): 719-726.

20. Ferguson GT, Feldman GJ, Hofbauer P, et al. Efficacy and safety of olodaterol once daily delivered via Respimat(R) in patients with GOLD 2-4 COPD: results from two replicate 48-week studies. Int J Chron Obstruct Pulmon Dis. 2014;9:629-645.

21. Celli B, Crater G, Kilbride S, et al. Once-daily umeclidinium/ vilanterol 125/25 mcg in COPD: a randomized, controlled study. Chest. 2014;145(5):981-991.

22. Maltais F, Singh S, Donald AC, et al. Effects of a combination of umeclidinium/vilanterol on exercise endurance in patients with chronic obstructive pulmonary disease: two randomized, double-blind clinical trials. Ther Adv Respir Dis. 2014;8(6):169-181.

23. Cope S, Donohue JF, Jansen JP, et al. Comparative efficacy of longacting bronchodilators for COPD: a network meta-analysis. Respir Res. 2013; $14: 100$.

24. Roskell NS, Anzueto A, Hamilton A, Disse B, Becker K. Once-daily long-acting beta-agonists for chronic obstructive pulmonary disease: an indirect comparison of olodaterol and indacaterol. Int J Chron Obstruct Pulmon Dis. 2014;9:813-824.

25. Agusti A, de Teresa L, De Backer W, et al. A comparison of the efficacy and safety of once-daily fluticasone furoate/vilanterol with twice-daily fluticasone propionate/salmeterol in moderate to very severe COPD. Eur Respir J. 2014;43(3):763-772.

26. Cope S, Capkun-Niggli G, Gale R, Jardim JR, Jansen JP. Comparative efficacy of indacaterol $150 \mu \mathrm{g}$ and $300 \mu \mathrm{g}$ versus fixed-dose combinations of formoterol + budesonide or salmeterol + fluticasone for the treatment of chronic obstructive pulmonary disease-a network metaanalysis. Int J Chron Obstruct Pulm Dis. 2011;6:329-344.

27. D’Urzo AD, Rennard SI, Kerwin EM, Mergel V, Leselbaum AR, Caracta CF; AUGMENT COPD study investigators. Efficacy and safety of fixed-dose combinations of aclidinium bromide/formoterol fumarate: the 24-week, randomized, placebo-controlled AUGMENT COPD study. Respir Res. 2014;15:123.

28. Singh D, Jones PW, Bateman ED, et al. Efficacy and safety of aclidinium bromide/formoterol fumarate fixed-dose combinations compared with individual components and placebo in patients with COPD (ACLIFORM-COPD): a multicentre, randomised study. BMC Pulm Med. 2014;14:178.

29. Yao W, Wang C, Zhong N, et al. Effect of once-daily indacaterol in a predominantly Chinese population with chronic obstructive pulmonary disease: a 26-week Asia-Pacific study. Respirology. 2014;19(2): 231-238.

30. Bateman ED, Ferguson GT, Barnes N, et al. Dual bronchodilation with QVA149 versus single bronchodilator therapy: the SHINE study. Eur Respir J. 2013;42(6):1484-1494.

31. Rossi A, Kristufek P, Levine BE, et al; Formoterol in Chronic Obstructive Pulmonary Disease (FICOPD) II Study Group. Comparison of the efficacy, tolerability, and safety of formoterol dry powder and oral, slow-release theophylline in the treatment of COPD. Chest. 2002;121(4):1058-1069.

32. Gross NJ, Nelson HS, Lapidus RJ, et al. Efficacy and safety of formoterol fumarate delivered by nebulization to COPD patients. Respir Med. 2008;102(2):189-197.

33. Kinoshita M, Lee SH, Hang LW, et al. Efficacy and safety of indacaterol 150 and 300 microg in chronic obstructive pulmonary disease patients from six Asian areas including Japan: a 12-week, placebo-controlled study. Respirology. 2012;17(2):379-389.
34. Donohue JF, Fogarty C, Lotvall J, et al. Once-daily bronchodilators for chronic obstructive pulmonary disease: indacaterol versus tiotropium. Am J Respir Crit Care Med. 2010;182(2):155-162.

35. Gotfried MH, Kerwin EM, Lawrence D, Lassen C, Kramer B. Efficacy of indacaterol 75 mug once-daily on dyspnea and health status: results of two double-blind, placebo-controlled 12-week studies. COPD. 2012; 9(6):629-636

36. Kerwin EM, Gotfried MH, Lawrence D, Lassen C, Kramer B. Efficacy and tolerability of indacaterol 75 mug once daily in patients aged $\geq 40$ years with chronic obstructive pulmonary disease: results from 2 double-blind, placebo-controlled 12-week studies. Clin Ther. 2011;33(12):1974-1984.

37. Feldman G, Siler T, Prasad N, et al. Efficacy and safety of indacaterol 150 microg once-daily in COPD: a double-blind, randomised, 12-week study. BMC Pulm Med. 2010;10:11.

38. Stockley RA, Chopra N, Rice L. Addition of salmeterol to existing treatment in patients with COPD: a 12 month study. Thorax. 2006;61(2): 122-128.

39. Chapman KR, Arvidsson P, Chuchalin AG, et al. The addition of salmeterol 50 microg bid to anticholinergic treatment in patients with COPD: a randomized, placebo controlled trial. Chronic obstructive pulmonary disease. Can Respir J. 2002;9(3):178-185.

40. Rutten-van Molken M, Roos B, Van Noord JA. An empirical comparison of the St George's Respiratory Questionnaire (SGRQ) and the Chronic Respiratory Disease Questionnaire (CRQ) in a clinical trial setting. Thorax. 1999;54(11):995-1003.

41. Calverley PM, Anderson JA, Celli B, et al. Salmeterol and fluticasone propionate and survival in chronic obstructive pulmonary disease. N Engl J Med. 2007;356(8):775-789.

42. Jones PW, Anderson JA, Calverley PM, et al. Health status in the TORCH study of COPD: treatment efficacy and other determinants of change. Respir Res. 2011;12:71.

43. Celli B, Halpin D, Hepburn R, Byrne N, Keating ET, Goldman M. Symptoms are an important outcome in chronic obstructive pulmonary disease clinical trials: results of a 3-month comparative study using the Breathlessness, Cough and Sputum Scale (BCSS). Respir Med. 2003;97(Suppl A):S35-S43.

44. Hanania NA, Darken P, Horstman D, et al. The efficacy and safety of fluticasone propionate $(250 \mathrm{microg}) / \mathrm{salmeterol}$ ( $50 \mathrm{microg}) \mathrm{com}-$ bined in the Diskus inhaler for the treatment of COPD. Chest. 2003; 124(3):834-843.

45. Calverley P, Pauwels R, Vestbo J, et al. Combined salmeterol and fluticasone in the treatment of chronic obstructive pulmonary disease: a randomised controlled trial. Lancet. 2003;361(9356):449-456.

46. Mahler DA, Wire P, Horstman D, et al. Effectiveness of fluticasone propionate and salmeterol combination delivered via the Diskus device in the treatment of chronic obstructive pulmonary disease. Am J Respir Crit Care Med. 2002;166(8):1084-1091.

47. Brusasco V, Hodder R, Miravitlles M, Korducki L, Towse L, Kesten S. Health outcomes following treatment for six months with once daily tiotropium compared with twice daily salmeterol in patients with COPD. Thorax. 2003;58(5):399-404.

48. Donohue JF, van Noord JA, Bateman ED, et al. A 6-month, placebocontrolled study comparing lung function and health status changes in COPD patients treated with tiotropium or salmeterol. Chest. 2002; 122(1):47-55.

49. Jones PW, Beeh KM, Chapman KR, Decramer M, Mahler DA, Wedzicha JA. Minimal clinically important differences in pharmacological trials. Am J Respir Crit Care Med. 2014;189(3):250-255.

50. Cope S, Capkun-Niggli G, Gale R, et al. Efficacy of once-daily indacaterol relative to alternative bronchodilators in COPD: a patient-level mixed treatment comparison. Value Health. 2012;15(3):524-533.

51. Donohue JF. Systematic review comparing LABA, olodaterol, and indacaterol: limitations. Int J Chron Obstruct Pulmon Dis. 2014;9: 1331-1333.

52. Dahl R, Greefhorst LA, Nowak D, et al. Inhaled formoterol dry powder versus ipratropium bromide in chronic obstructive pulmonary disease. Am J Respir Crit Care Med. 2001;164:778-784. 
International Journal of COPD

\section{Publish your work in this journal}

The International Journal of COPD is an international, peer-reviewed journal of therapeutics and pharmacology focusing on concise rapid reporting of clinical studies and reviews in COPD. Special focus is given to the pathophysiological processes underlying the disease, intervention programs, patient focused education, and self management protocols.

This journal is indexed on PubMed Central, MedLine and CAS. The manuscript management system is completely online and includes a very quick and fair peer-review system, which is all easy to use. Visit http://www.dovepress.com/testimonials.php to read real quotes from published authors 